\title{
HIBROWSE for Hotels: Bridging the Gap Between User and System Views of a Database
}

\author{
G P Ellis, J E Finlay, A S Pollitt Centre for Database Access Research and Human \\ Computer Interaction Research Centre, \\ University of Huddersfield, UK
}

\begin{abstract}
Database theory and technology has traditionally been concerned with issues such as consistency and efficiency rather than usability. This has led to interaction styles which focus on the structure of the database, which is system-based, rather than the user's view of its content Therefore the problem that needs to be addressed is that of bridging the gap between the user's model of the data and that of the system. The system presented here. approaches this problem by presenting the user with a domain oriented view of the database. Access is then achieved by manipulating the contents of the database rather than the structure.
\end{abstract}

\section{Introduction}

Database theory and technology has traditionally been concerned with issues such as consistency and efficiency rather than usability. This is important, particularly with large databases, but has led to interaction styles which focus on the structure of the database rather than its content.

Unfortunately the ideal structure from an implementational and theoretical viewpoint may not reflect the user's view or model of the data, which is governed by knowledge of the domain rather than of the database itself. Such a mismatch between user and system models can lead to problems in accessing the data, since access methods demand an understanding of the database structure in addition to domain knowledge.

The increasing reliance on databases as tools for use in diverse applications by a range of users has led to a recognition of the need to facilitate database access. Approaches to this vary. Some recent database systems, both commercial (such as Microsoft Access ${ }^{\mathrm{TM}}$ and Quest ${ }^{\mathrm{TM}}$ from Gupta Europe) and research systems $[1,2]$.

employ graphical user interface techniques which have the advantage of providing the user with cues to understanding the structure of the database and composing queries. While an improvement on command style query languages such systems do not address the underlying problem of the focus on the system rather than the user view.

Approaches such as Query-by-Example begin to address this issue. Here the user is presented with a view of the database structure and is able to specify "example" values for particular fields as a means of accessing the data (Figure 1).

"Display the Green Items" [3]

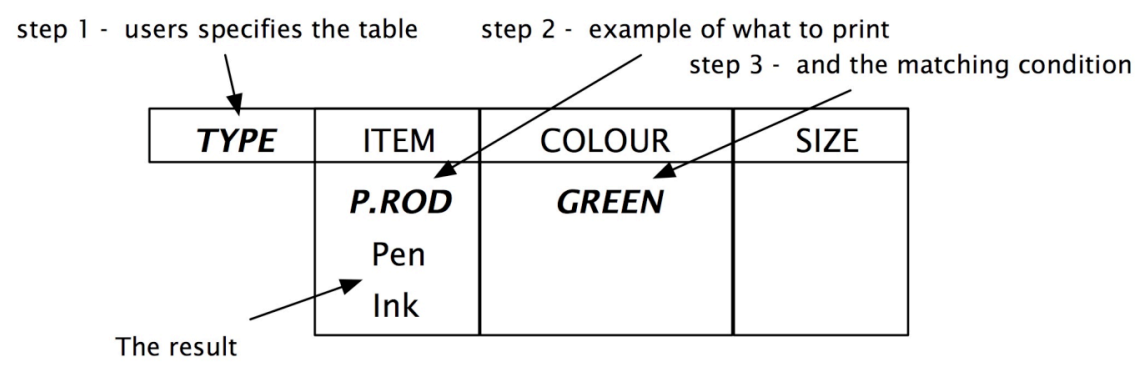

Figure 1: An example of Query-by-Example

This has proved to be successful for certain database applications but the approach still presents the user with the underlying structure of the database (which may not reflect the user's interests) and requires some understanding of this structure and of appropriate example values. This can be problematic if the user has insufficient knowledge of the database to select the necessary examples or tables or to evaluate the system's response.

In our view the problem that needs to be addressed is not simply that of making the interface more 
accessible or even the structure more explicit but that of bridging the gap between the user's view of the data and that of the system. HIBROWSE, the system discussed here, approaches this by presenting a view of the database which reflects the interests of the user. Access is achieved by manipulating the displayed database contents not by queries based on the structure. This approach has several advantages for the user. Access does not require an understanding of the structure of the database, making it more intuitive. Consequently queries can be produced far more quickly than with conventional access techniques and, additionally, the user is able to browse the database contents.

HIBROWSE is designed with the principle of interface separation in mind: the application is distinct from the interface and the two are linked by a dialogue controller. This architecture has a number of advantages:

- it allows the presentation of an alternative view of the database while retaining the database application unchanged;

- $\quad$ it supports reusability and portability;

- $\quad$ it allows continued use of the existing application facilities in parallel to the new functionality provided through HIBROWSE

In the following sections we will explore the design and implementation of a prototype application of HIBROWSE, developed for the Hotel and Catering Research Centre at the University of Huddersfield, identifying issues associated with the interface, application database and dialogue control.

\section{HIBROWSE for Hotels}

HIBROWSE has its origins as Query-by-Menu, a system first described by Pollitt [4]. It was compared with Query-by-Example [5], and shown to be less complex for an end-user to employ in the specification of a search. The approach has been further developed and applied through a number of database applications, such as INSPEC [6] and the Hotels application considered here.

\subsection{The Motivation}

The Hotel and Catering Research Centre (HCRC) is based in the Department of Food, Nutrition and Hospitality Management and amongst other activities maintains a comprehensive database of up-todate information on UK hotels and hotel companies. This includes details on over 3400 hotels which are owned by hotel groups or are members of one or more hotel consortia. A summary of the structure of the database is given in Figures 2 and 3. The HCRC publishes a paper directory, the UK Hotels Groups Directory, and also offers a consultancy service to companies with interests in the hotel industry. Clients are typically interested in receiving information on those hotels, groups or consortia which meet certain criteria (for example, 3 star AA rating and above with 200 or more bedrooms in North England and Scotland) or for information on a particular company which includes hotel details and summaries of the data by geographic region, star rating and number of bedrooms.

Prior to using HIBROWSE, the Hotels database was queried using SQL, a structured command language. This requires a knowledge of the database tables and associated fields in addition to experience of formulating queries obeying the SQL syntax. This placed an unnecessary burden on the staff, and although they usually managed to answer a client's request for specific information, the average time taken to undertake each request was half a day. Therefore the staff did not have sufficient time to process all the consultancy requests they received and it was actually considered uneconomic, in terms of the time taken, to process these requests using the existing system.

\subsection{Requirements for HIBROWSE for Hotels}

In addition to the primary requirement of supporting the consultancy task described above, other requirements were identified in consultation with the staff in the HCRC. One of these was for the research staff to be able to browse through the data to identify trends and statistical information. For example, an analysis of the hotel consortia based on the number of bedrooms. Another was to cater for the wide range of document and file formats requested by the clients. These include the ability to produce files for export to the client's own database, comprehensive sort and selection options and the production of cross reference data. Not only were these requirements difficult to meet using SQL but most of them required some form of post processing on the data.

\subsection{The Database}

The Hotels relational database is held on an ORACLE DBMS running on a Sun 670 server and is accessed over the University's campus network. The main structure and tables of the database are illustrated in Figures 2 and 3. 


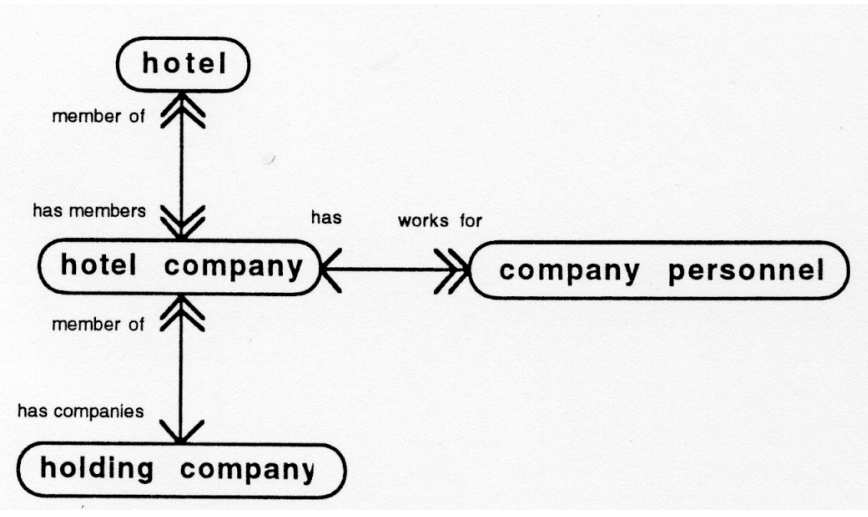

Figure 2: Entity-Relationship diagram for the Hotels database

hotel (hotel_code, name, street, city, county, country, tourist_board_area, postcode, phone, telex, fax, aa_rating, rac_rating, rooms, hotel_type)

hotel_company (hotel_company_code,company_type, holding_company_no, name, street, city, county, country, postcode, phone, telex, fax)

holding_company (holding_company_code, name, street, city, county, country, postcode, phone, telex, fax)

membership (hotel_company_code, hotel_code)

company_personnel (hotel_company_code, name,position)

Figure 3: The main tables in the Hotels database

\subsection{A Typical SQL Query on the Hotels Database}

As part of their consultancy, the HCRC may have a request from a client for information on hotels and the companies with interests in these hotels meeting the following criteria: "3 star AA rating and above with 200 or more bedrooms in North England and Scotland"

A) To retrieve the information on the hotels the following SQL query would be required:

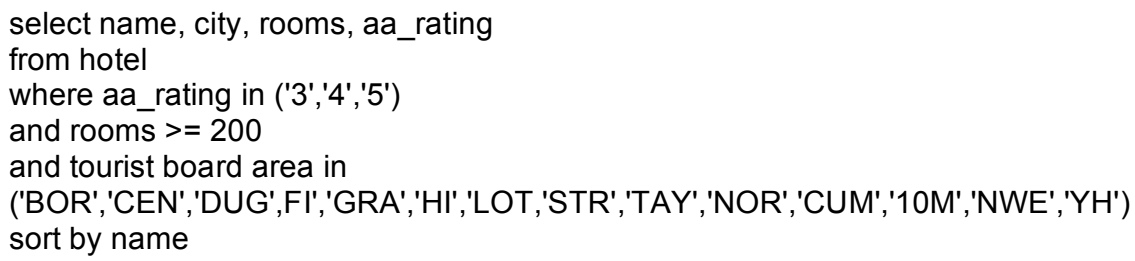

B) To retrieve a summary of information on the hotel companies with interests in those hotels the following SQL query would be required:

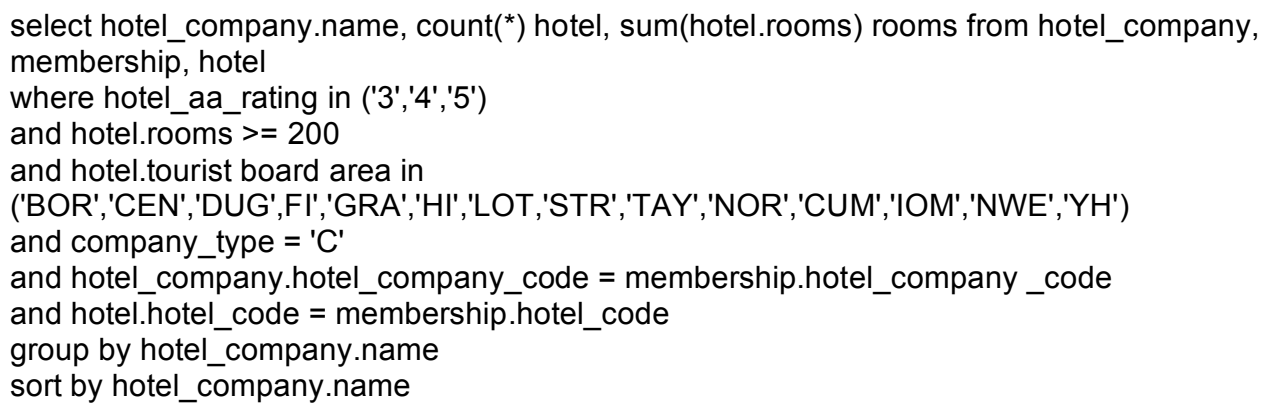

It can be seen that even with this is a relatively simple query the researcher needs a good knowledge of the structure of the database (e.g. the appropriate field and table names), the various coding scheme used in the database (e.g.. the tourist board area codes) and a good knowledge of formulating an SQL query (e.g. the 'group' command used in example B for producing summary information).

Bearing in mind that the data retrieved by these query statements also requires editing on a word processor into the appropriate form for the client (this often took a significant time in the HCRC), the total effort required is considerable, even for this simple example. 


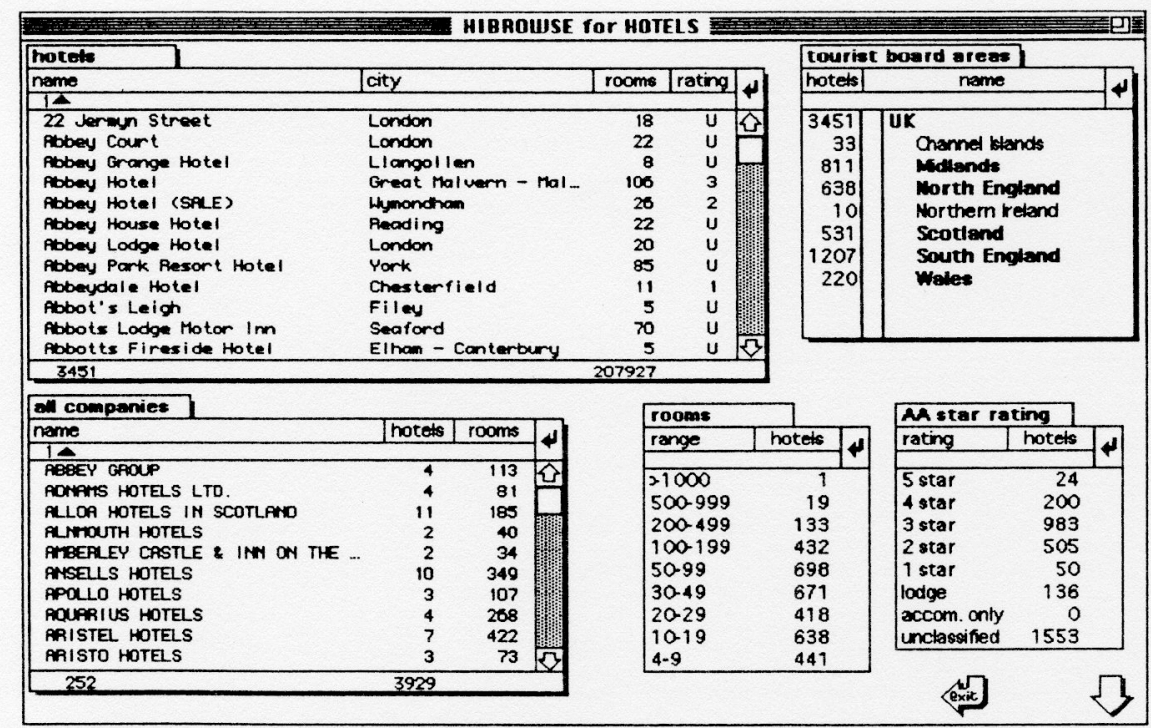

Figure 4: HIBROWSE for Hotels top level

\subsection{The HIBROWSE Interface}

Figure 4 shows the top level screen of the HIBROWSE interface for the HCRC Hotels database. The main characteristics of HIBROWSE are that it presents a view of the contents of the database to the user and allows the user to search and browse the database by selection of the contents. The presentation of this information is achieved using a number of windows, each one presenting either

i. raw data, as in the hotels window which shows the name, city, number of bedrooms and star rating values for each hotel

ii. summary information, as the AA star rating, rooms and tourist board areas windows

iii. related data, as in the companies window which shows those hotel companies which have interests in the hotels.

The summary information windows in HIBROWSE for Hotels present data from the database in different ways. The AA star rating window, shows a straightforward count of the number of hotels with each rating. The rooms window shows a count of the number of hotels within prescribed room ranges, aggregating the values in the database. The tourist board areas window presents the data based on the geographical location in the UK. This is a hierarchical view; at the top UK level it gives the number of hotels in each of the large regions such as South England, but allows the user to browse down to a lower level to get more information on the number of hotels in the actual tourist board areas (Figure 5). This presentation method is based on the MenUSE interface being developed at CeDAR [7].

It is clear from the top level screen (Figure 4) that a significant amount of information is presented to the user, without the user even asking a question of the system. For example, there is only 1 hotel with 1000 or more rooms; according to the AA star rating scheme there are 136 lodges and 245 star hotels; there are only 10 hotels in Northern Ireland which belong to hotel groups or consortia; and there is a hotel called "22 Jermyn Street" in London.

Additional functionality is provided by allowing the user to customise, where appropriate, the windows in order to alter the way the data is presented. For example, if the user is interested in seeing the largest hotels, according to number of bedrooms, then the user selects rooms in the hotels window and the data is sorted by rooms as shown in Figure 5. (The user could easily change the sort direction to ascending if the area of interest was in the smallest hotels). Similarly, Figure 5 shows the companies window sorted by number of hotels in the consortia, with a secondary sort on the total number of rooms (as indicated by the value 2 next to the sort direction indicator triangle). Figure 5 also shows that the summary information on star rating has been changed to RAC instead of AA. This illustrates another feature of HIBROWSE which, where appropriate, gives the user the additional flexibility of changing the view of the data. 


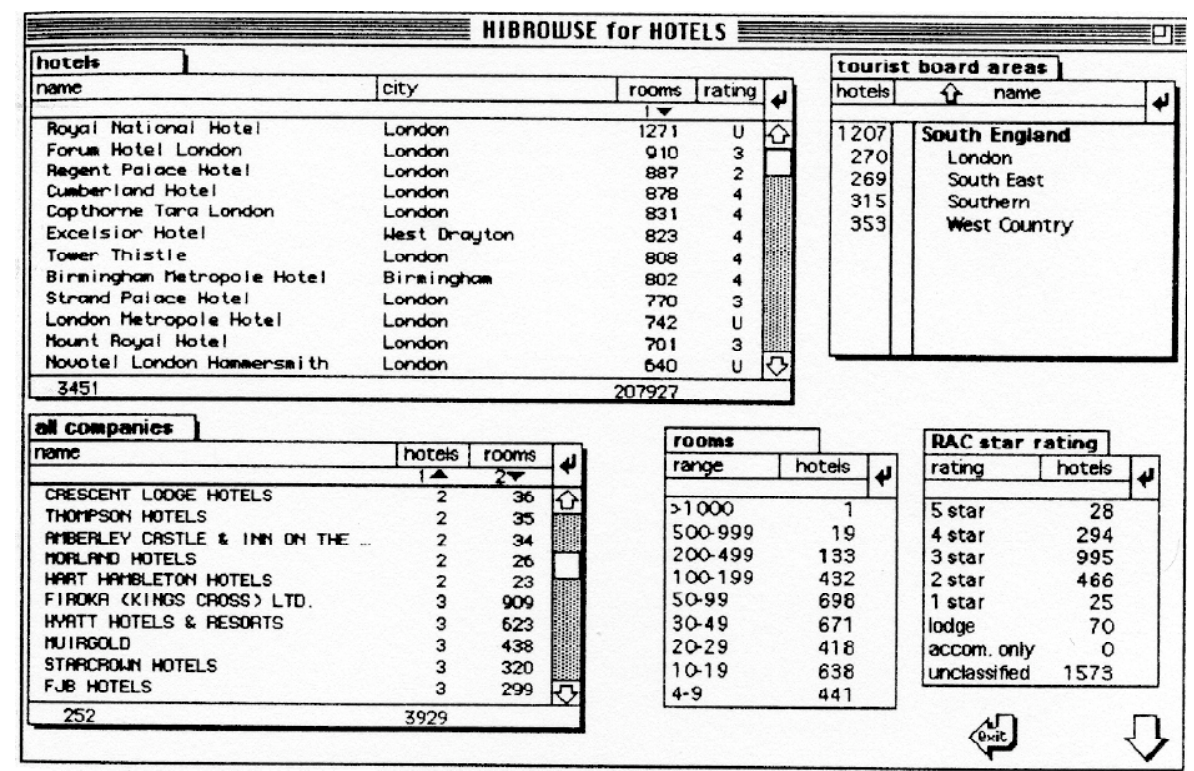

Figure 5: HIBROWSE for Hotels top level showing different sort criteria and also browsing the tourist board area window to show the South of England regions

\subsection{Querying the Database}

The previous section described the HIBROWSE interface and how the user can customise their view of the data. This section illustrates how the user queries the database in HIBROWSE and can be compared to the SQL query given earlier to retrieve those hotels matching particular criteria i.e. "3 star AA rating and above with 200 or more bedrooms in North England and Scotland"

The user highlights the required star. ratings and room ranges and selects North England and Scotland regions (Figure 6).

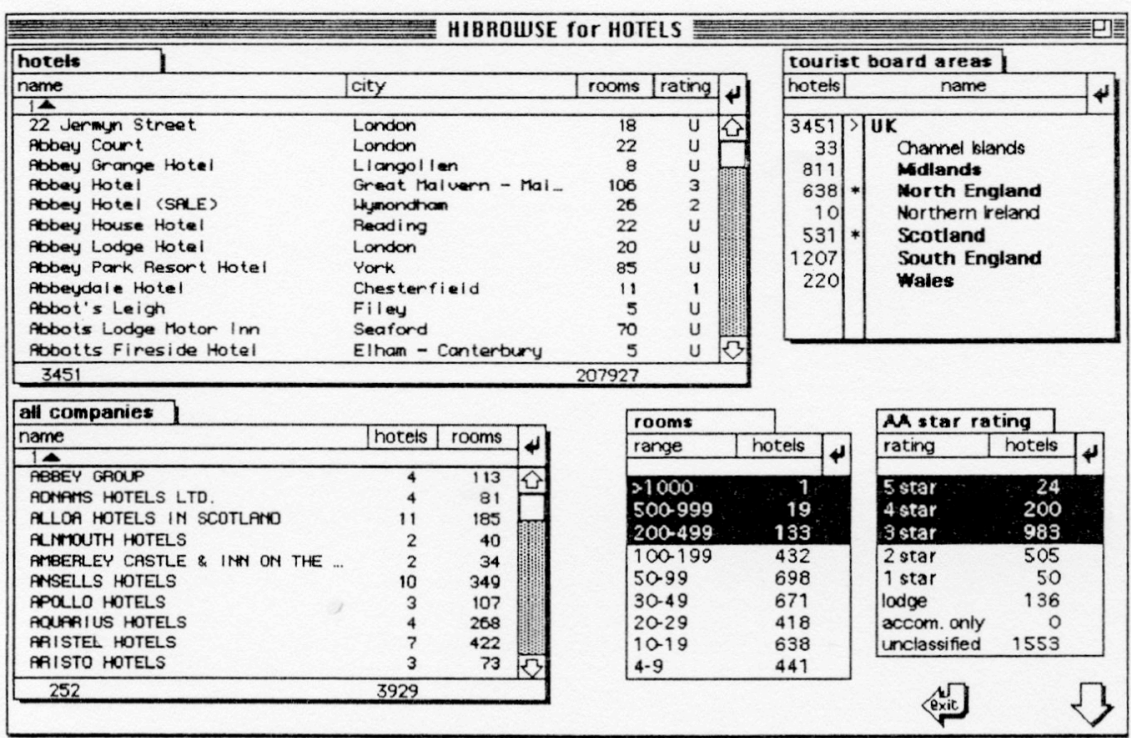

Figure 6: HIBROWSE for Hotels - top level with selections

No search takes place until the down arrow is selected and a new HIBROWSE screen is presented, giving the user the view of the database matching the chosen criteria (Figure 7). 


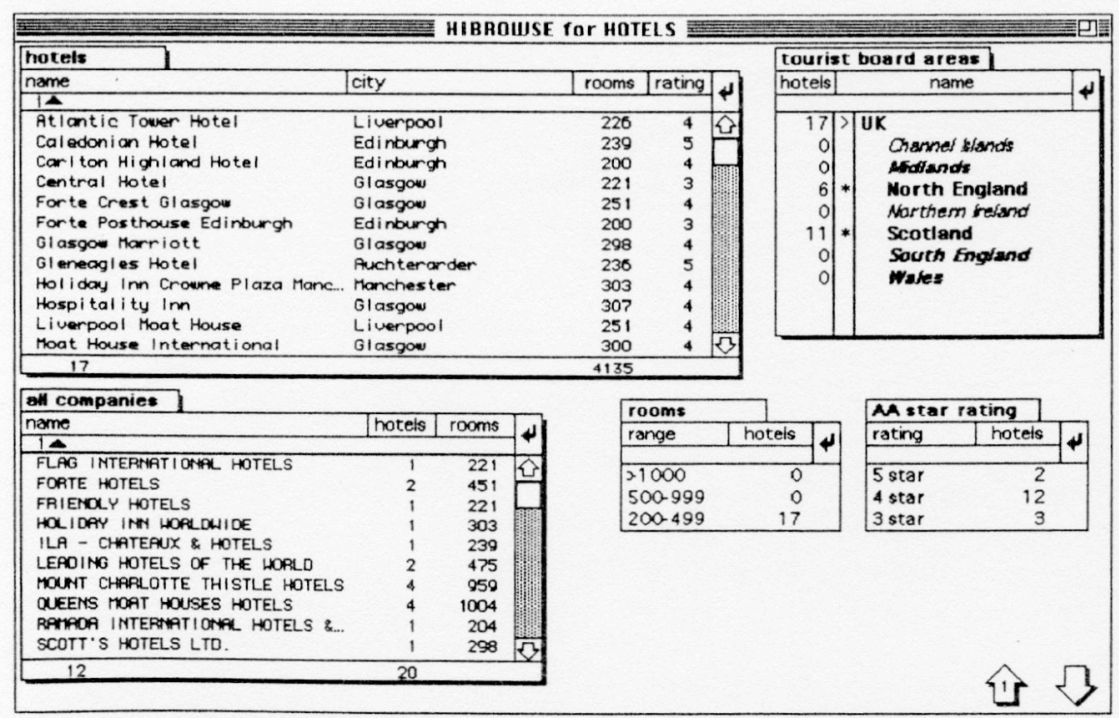

Figure 7: HIBROWSE for Hotels for 3 star AA rating and above with 200 or more bedrooms in North England and Scotland

All the windows are automatically updated to reflect this and the user is free to scroll through the lists of hotels and companies as well as sorting the order of the data as required.

With a minimum of effort on behalf of the user, both of the example queries have been answered. In addition a large amount of 'extra' information has been presented. For example, of the 17 hotels only 2 have a 5 star rating, 6 are in North England and there are no hotels with 500 or more bedrooms. To see the consortia to which the hotels belong, the companies window can be easily changed (Figure 8).

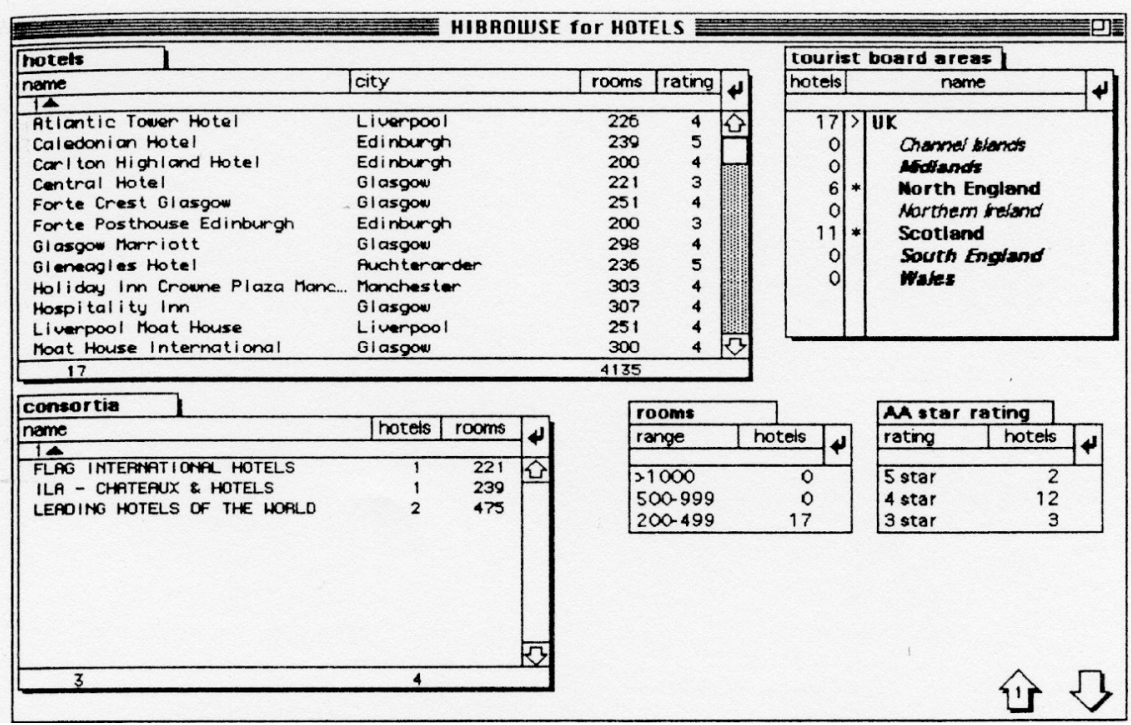

Figure 8: HIBROWSE for Hotels for 3 star AA rating and above with 200 or more bedrooms in North England and Scotland, showing information on the consortia with members in this range.

\subsection{Browsing the Database}

In the previous example the user was seeking specific information. HIBROWSE also permits the user to browse the database, gradually refining the query. At each stage the user is presented with an updated view of the database which both provides an intermediate result and serves as the source for selections at the next stage. This supports the principle of equal opportunity [8] to the extent that the distinction between input and output is blurred. Instead of being forced to cycle between request and result, the user can browse the contents of the database viewing any item as input or output.

This is best illustrated through a worked example. Our client is interested in hotels in Cumbria. The user selects North England from the region window and selects the 89 hotels shown to be in Cumbria (Figure 9). 


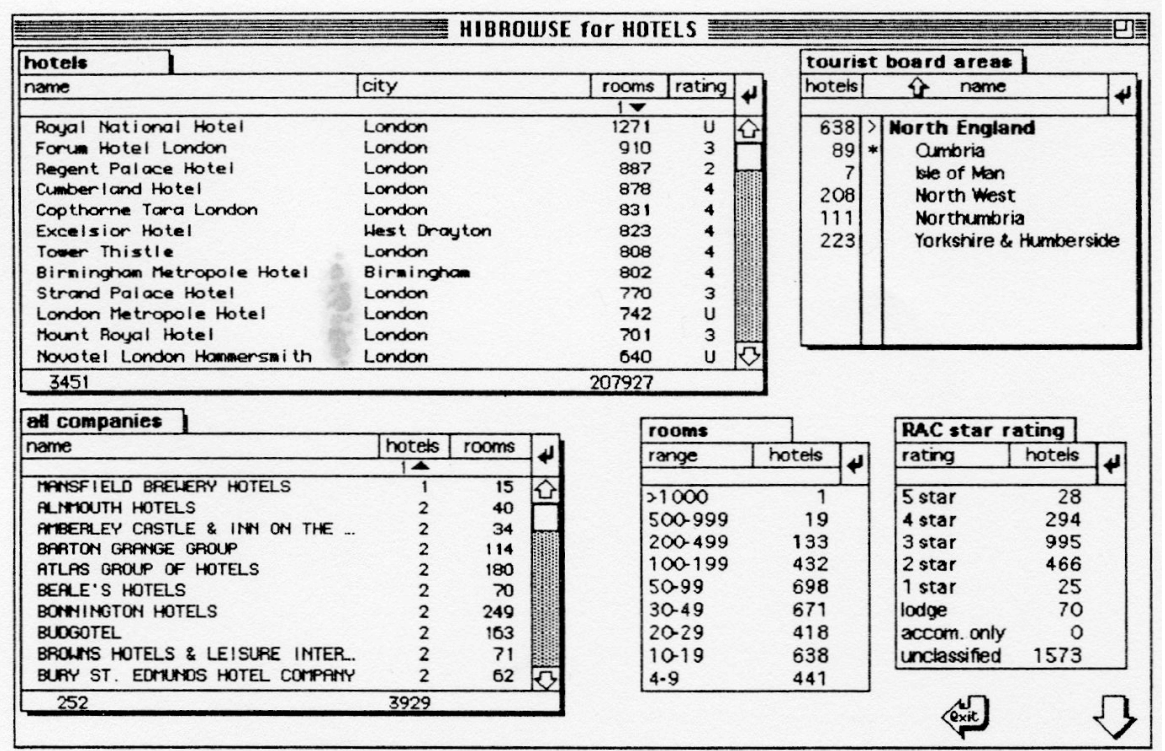

Figure 9: HIBROWSE for Hotels top level with Cumbria selected

The resulting HIBROWSE screen is shown in Figure 10. The user has sorted the hotels by city and observes that there are three in Ambleside.

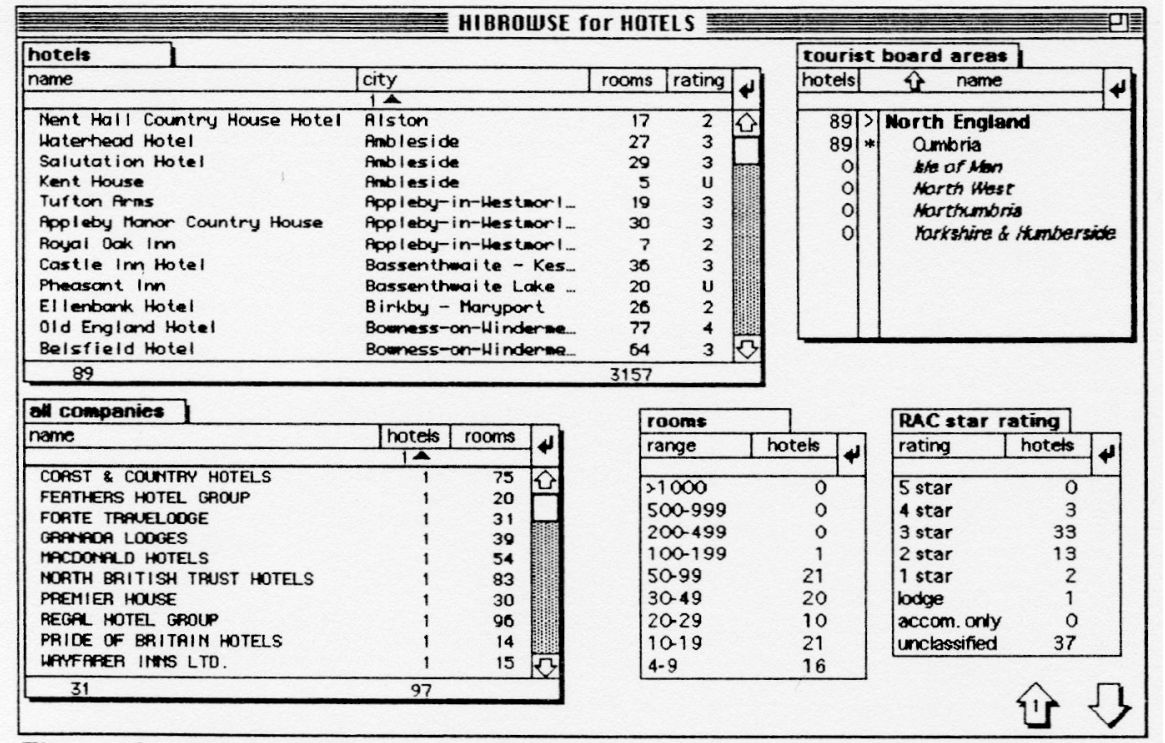

Figure 10: HIBROWSE for Hotels showing information on the hotels in the Cumbria tourist board area

Selecting one of these, the Waterhead Hotel, the user is presented with further information (Figure 11). It can be seen that this hotel is a member of ENGLISH LAKES HOTELS. To see what other hotels are in this company, the user simply highlights this from the list shown in the companies window and selects the down arrow to activate the search. The new HIBROWSE screen (Figure 12) shows the four hotels associated with the company. Note that three of these hotels are also members of BEST WESTERN HOTELS. 


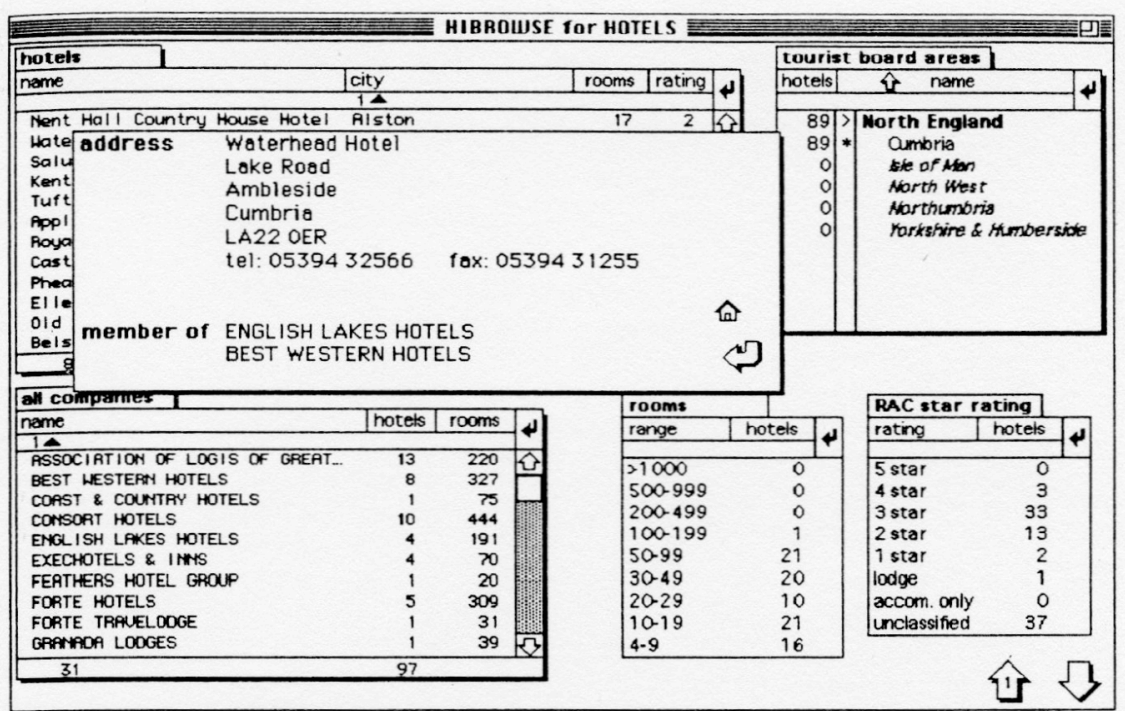

Figure 11: HIBROWSE for Hotels showing additional information for the Waterhead Hotel in Ambleside

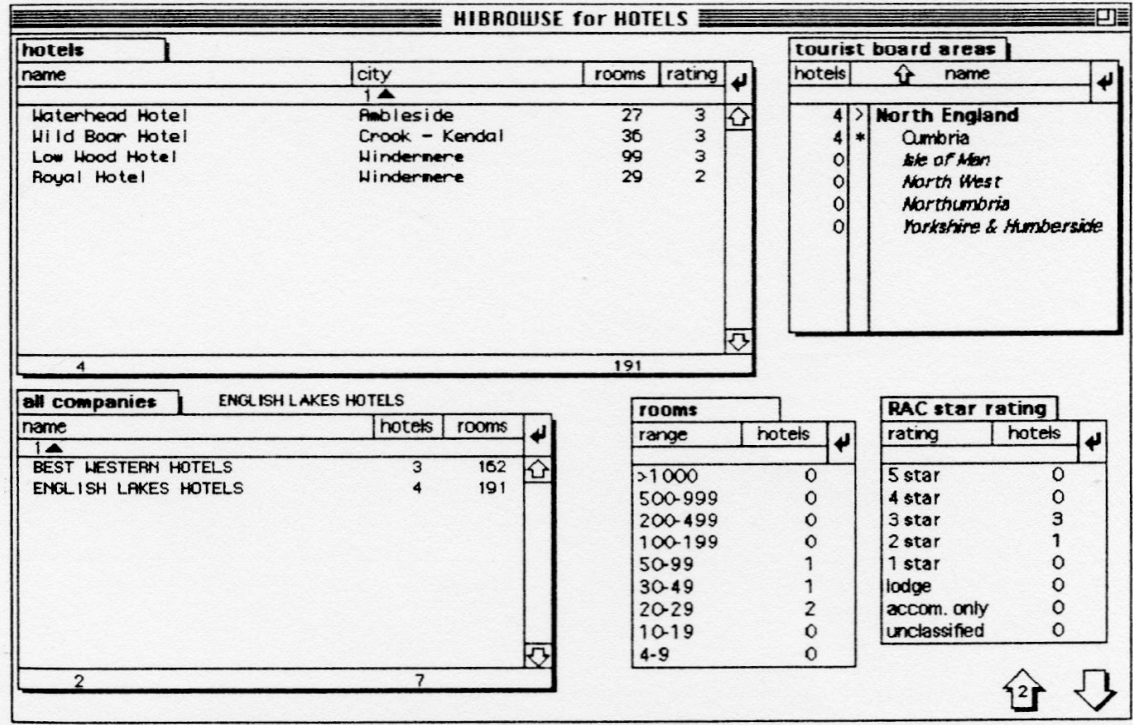

Figure 12: HIBROWSE for Hotels showing in Cumbria which are members of ENGLISH LAKES HOTELS

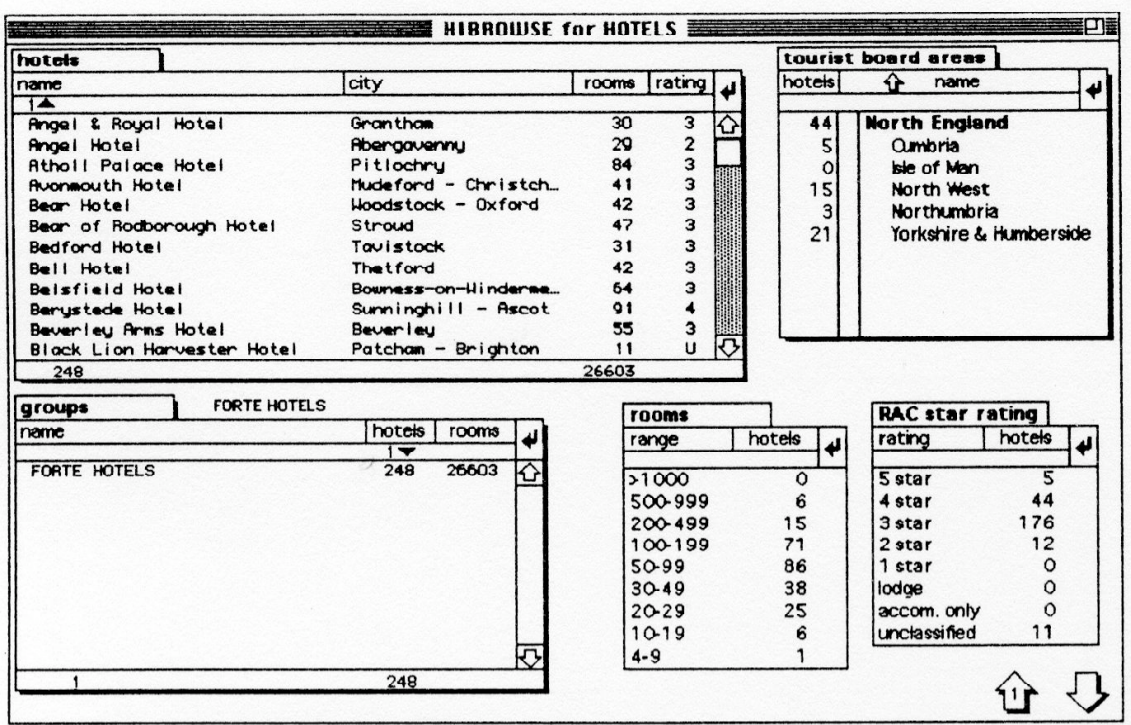

Figure 13: HIBROWSE for Hotels showing information on the hotels belonging to the FORTE HOTELS group 
A valuable feature of HIBROWSE for Hotels is the ease with which a summary of information on a particular hotel company can be produced. Figure 13 shows information on FORTE HOTELS It can be immediately seen that the majority of FORTE HOTELS are of 3 star RAC rating and that most have between 50 and 200 rooms. It is also apparent that most of the hotels in North England are in the North West and Yorkshire \& Humberside tourist board areas.

\subsection{The Dialogue Control}

All the information presented to the user is retrieved from the ORACLE database server and is independent of the client computer.

The application has been developed in HyperCard 2.1 on the Macintosh and uses ORACLE SQL *Net, ORACLE's HyperCard XCMD and MacTCP to access the Sun 670 database server over the University's campus network.

Database structure has not been altered to accommodate HIBROWSE. The only additional database table is a lookup table which gives the tourist board area codes, used in the original database, for the regions shown in the tourist board area window.

The functionality of HIBROWSE is achieved by generating and sending SQL type requests to ORACLE and parsing the data which is returned. For each new HIBROWSE screen, a database 'view' is created based on the current selections made by the user. Each window is then updated using this 'view' together with the current sort criteria for that particular window. This approach reduces the length of SQL queries which have to be sent to the DBMS.

\subsection{The System in Practice}

HIBROWSE for Hotels was developed with the cooperation of the HCRC. The system has been evaluated using an approach based on cooperative evaluation [9]. This has involved the users of the system "walking through" common tasks in HIBROWSE and "thinking aloud", describing their actions and their reactions to the new system. This led to the installation of the first version in March 1993 which has been used successfully since then with only minor modifications.

The main responses from the users can be summarised as follows:

i. The learning time was very short even for users with no previous knowledge of the Hotels database.

ii. The rapid response to consultancy requests was impressive. The substantial reduction in time even permitted the HCRC staff to respond immediately to requests over the telephone.

iii. The ability to browse the database was found very useful for the research staff especially when preparing commentaries on hotel companies.

iv. Users made far fewer errors than with SQL, where syntax errors were common. In HIBROWSE the user is protected from this type of error and any errors that occur in browsing are easily recovered from through altering the selections made and backtracking.

v. Although not illustrated in this paper, the flexible document production options associated with HIBROWSE for Hotels, used together with the sort criteria for the hotel and companies windows, provided the HCRC with an expanded consultancy market, as they could produce computer files in many different formats suitable for importing to the clients' own databases.

\section{The Future for HIBROWSE}

Response from users in initial trials and the longer term use of HIBROWSE for Hotels suggests that this mode of database access does bring substantial gains both in productivity and user satisfaction. The view the users have of the database reflects their existing domain knowledge and allows them to manipulate data and perform searches in terms of the domain rather than in terms of the underlying database.

Various usability issues have yet to be resolved including:

i. How the system should deal with the arrangement of windows, especially if there are too many to fit on the screen at one time.

ii. The problem of presenting many-to-many relationships in that it has to be obvious to the user that the contents of one window reflects the selections made in another.

iii. Direct access to a hotel by perhaps entering tile first characters of its name. This also applies to regions when the user is not sure in which area of the UK it is located. 
The use of separation as a paradigm for the design has been beneficial in a number of ways. It avoids the need to alter the underlying database application which means that existing databases can be provided with the functionality of HIBROWSE without modification. It also means that the approach is portable and can in theory be applied to any relational database. Other example HIBROWSE applications have been developed for various databases, for example INSPEC and EPOQUE (European Parliament Online Query System) to illustrate this principle [6]. Current work is concentrating on the development of a toolkit to support the rapid generation of HIBROWSE applications for relational databases.

\section{References}

[1] Weiland W, Shneiderman B. A graphical query interface based on aggregation/generalisation hierarchies. Info Systems 1993; 18; 4:215-232

[2] Young D, Shneiderman B. A Graphical Filter/Flow Representation of Boolean Queries: A Prototype Implementation and Evaluation. JASIS 1993; 44; 6:327-339

[3] Zloof M M. Query-by-Example. a database language. IBM Systems Journal 1977; 16; 4:324343

[4] Pollitt A S. Query-by-Menu: A novel DBMS query language, a description and comparison with $Q B E$. 8th BCS IRSG Research Colloquium on Information Retrieval, University of Strathclyde, 1986

[5] Zloof M M. Query-by-Example. In Proceedings of the National Computer Conference, Vol 44, pp431-438, Arlington, V A, AFIPS Press

[6] Pollitt A S, Ellis G P, Smith M P. HIBROWSE - Adding the power of relational databases to the traditional $l R$ architecture - the future for Graphic User Interfaces. 15th BCS IRSG Research Colloquium on Information Retrieval, University of Strathclyde, 1993

[7] Pollitt A S, Ellis G P. Multilingual access to document databases. CAIS/ACSI '93 Information as a Global Commodity - Communication, Processing and Use. 21st Annual Conference of the Canadian Association for Information Science, Antigonish, Nova Scotia, Canada, 1993, pp 128140

[8] Thimbleby H. User Interface Design, Addison Wesley, 1990

[9] Monk A F, Wright P C, Davenport L and Haber J. Improving your human computer interface: A practical technique. Prentice Hall Practitioner Series, 1993 